\title{
The suitability of the ultrasound biomicroscope for establishing texture in giant cell arteritis
}

\author{
Sigrid Roters, Peter Szurman, Bert F Engels, Richard Brunner
}

\begin{abstract}
Aim-To establish whether ultrasound biomicroscope (UBM) is a helpful tool in locating the arterial segment responsible in patients with segmental attacks in giant cell arteritis

Methods-The superficial temporal arteries of 19 patients with suspected giant cell arteritis were examined with the UBM before biopsy.

Results-20 specimens provided the histological proof of giant cell arteritis in five patients. Side differences, a dark perivascular halo, and high reflexivity of the intra-arterial space were found.

Conclusion-it is assumed that there are two types of arteritic inflammation: (1) the occlusion of intra-arterial space due to intimal fibrosis (UBM: high reflexive "filling"), and (2) inflammation of the perivascular zone with oedematous thickening and infiltration of the media (UBM: dark halo) and its combination. UBM is helpful in obtaining an indication of the side and segment for biopsy.

(Br F Ophthalmol 2001;85:946-948)
\end{abstract}

Giant cell arteritis can be diagnosed on the basis of clinical findings, but a temporal artery biopsy is generally recommended to confirm the diagnosis. ${ }^{1}$ The American College of Rheumatology requires that three out of five criteria are met in order to obtain a correct diagnosis: age $\geqslant 50$ years; new onset of localised headache; temporal artery tenderness or decreased pulse; erythrocyte sedimentation rate $\geqslant 50 \mathrm{~mm}$ in the first hour; and histological findings. ${ }^{2}$

A biopsy of the superficial temporal artery is usually a safe, well tolerated procedure which can be performed under local anaesthesia but involves an invasive surgical examinationcomplications have been described..$^{3-5}$ Obtaining the histological results is time consuming. The high frequency ultrasound biomicroscope (UBM) seems to be very suitable for imaging the superficial temporal artery, which is located on the fascia temporalis 3-4 $\mathrm{mm}$ under the surface of the skin. We wanted to obtain an indication of the location of the arterial segment.

\section{Materials and methods}

In this prospective study, 19 patients suffering from suspected active giant cell arteritis were treated from September 1997 to September 1998. Clinical data were recorded in nine men and 10 women aged $50-89$ years (mean 71.3 years) including erythrocyte sedimentation rate and Doppler sonography to rule out collateral circulation as well as the evaluation of the appearance of the temporal artery. ${ }^{6}$ Written informed consent for temporal artery biopsy was given. Before surgery (maximum 24 hours), the temporal arteries were investigated using the ultrasound biomicroscope (Humphrey Instruments Inc Zeiss group, 50 $\mathrm{MHz}$ probe). The dimension and reflex of the arterial lumen and wall were evaluated. Suspicious locations were marked on the skin in order to perform the biopsy exactly from this part of the artery. When side differences were observed, the side and segment with the greater contraction of the temporal artery was chosen for biopsy. An ultrasound examination gel of low viscosity was used in order to avoid pressure during the investigation.

Twenty specimens, 10 right and 10 left side, were obtained without complications. The temporal artery of one patient was excised bilaterally. The sonographic observations and results were correlated with the histopathological changes.

\section{Results}

Five of the 19 patients examined showed histological evidence of giant cell arteritis.

Clinically, a sudden loss of vision $=0.1$ was observed four times in the giant cell arteritis group (five patients) and six times in the nonarteritic group (14 patients). We found erythrocyte sedimentation rate alterations in the range from 61 to $104 \mathrm{~mm}$ (arteritic group) and 2-90 mm (non-arteritic group). A suspect palpation was noticed in four of the five patients with giant cell arteritis. All of them had received corticosteroids for less than 6 days.

The following different sonographic conditions were observed only in the giant cell arteritis group:

- a hypoechoic halo around the arterial lumen (see Fig 1A) (three patients in the arteritic group). The light microscopy showed a diffuse chronic inflammatory infiltrate and thickening which spread throughout the media (see Fig 1B).

- an intra-arterial middle reflexive "filling" (Fig 2A) (three patients of the arteritic group).

The light microscopy showed a reduced lumen due to intimal thickening (see Fig 2B)

- a side difference between right and left artery

The side with the greater contraction of arterial lumen was chosen for biopsy-the effect was observed in three patients (all in the arteritic group).

Further observations were:

- high reflex of the arterial wall (see Fig 2A) (not only in patients of arteritic group, but in eight patients of the non-arteritic group) 

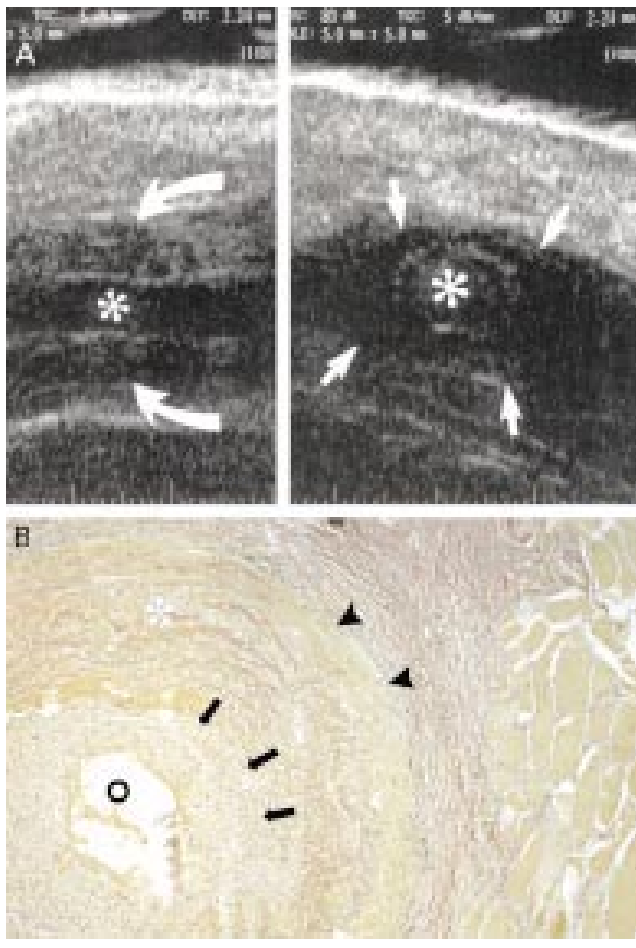

Figure 1 (A) UBM image with arteritic changes of the temporal artery - longitudinal section left, cross section right. Hyporeflexive halo (white arrows) around the intra-arterial lumen (asterisk). (With consent of Springer Verlag, Berlin and Heidelberg, from Roters S, Krieglstein GK, Atlas der Ultraschall-Biomikroskopie, 2001). (B) Light microscopy (van Gieson, original magnification) of artery with inflammatory changes. Small lumen (black circle). Intimal layer (black arrows) is thickened. In the media, the elastic lamina (black arrowheads) is fragmented and partially absent. A diffuse chronic inflammatory infiltrate is spread throughout the media (white asterisk).

- a kinetic sign of intravascular movement (two patients of the non-arteritic group)

- three patients had a large intra-arterial lumen (non-arteritic group)

- four patients showed bad imaging; only wall and lumen could be identified (non-arteritic group)

- very small lumina were observed in nine patients (two arteritic group, seven nonarteritic group).

- large wall dimensions were revealed in 10 patients (three arteritic group, seven nonarteritic group).

\section{Discussion}

There are several alternatives to the temporal artery biopsy - for example, angiographic imaging of the temporal artery. ${ }^{6}$ Using conventional ultrasonography $(10 \mathrm{MHz})$ Brosig et al and using Doppler sonography Dörnberger et $a l^{8}$ showed that the vessel course can be detected as well as the vessel diameter, plaques, stenosis, and the perivascular tissue of extracranial vessels. It is possible to arrive at a fast first documentation in many inflammatory and arteriosclerotic diseases. Since high resolution ultrasonographs have become commercially available, there is an increased expectation of improved non-invasive vascular imaging.

There are two main types of arteritic changes that show a close correlation with the UBM images:
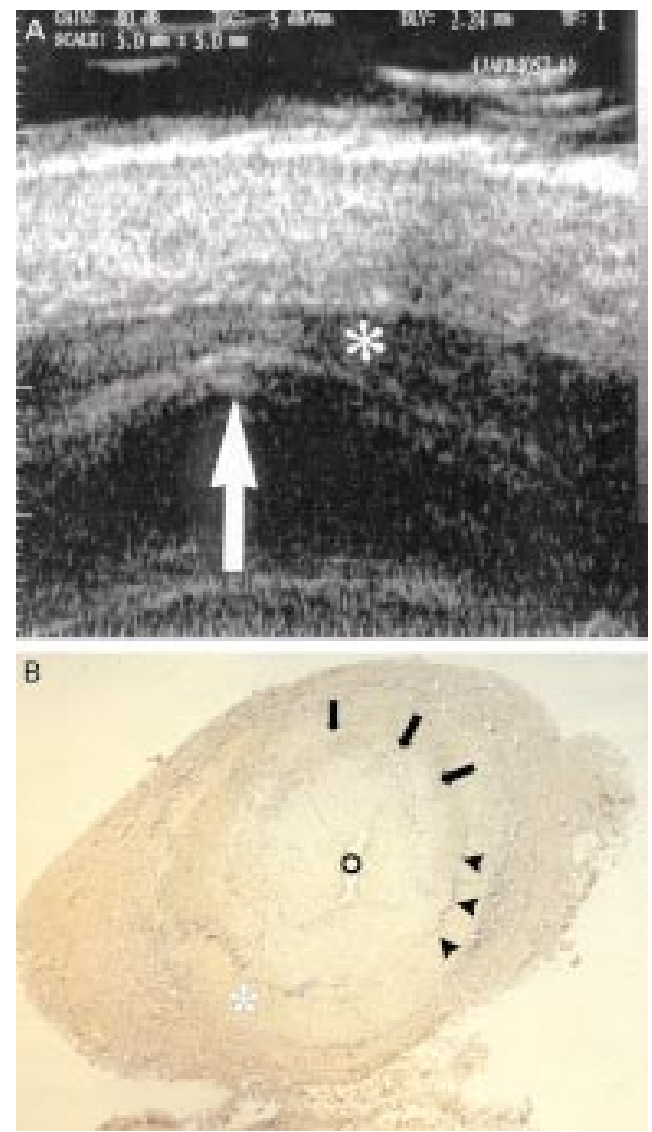

Figure 2 (A) UBM image with arteritic changes of the temporal artery - longitudinal section. Middle reflexive filling of the intra-arterial lumen (asterisk). Note the high reflexivity of the arterial wall and the thinning of the artery due to a tortuous run (arrow). (With consent of Springer Verlag, Berlin and Heidelberg, from Roters S, Krieglstein GK, Atlas der Ultraschall-Biomikroskopie, 2001). (B) Light microscopy (Elastica, original magnification) of an artery. The central lumen (black circle) is largely reduced. This is mostly because of intimal thickening (dark arrows). The media is not thickened (white asterisk). Fragmentation of the internal elastic lamina (black arrowheads) and chronic inflammatory infiltrates are present.

(1) The inflammation spills into the media, which is oedematous, congested, and thickened (UBM: dark halo) (see Fig 1).

(2) The intimal layer is greatly thickened by fine collagenous tissue with severe restriction of the lumen (UBM: intra-arterial "filling").

The normal sized muscularis media appears as the arterial wall (see Fig 2).

Both changes lead to a decrease in arterial lumen width and can be observed simultaneously.

Histologically, two patterns of the affected arteries can also be observed ${ }^{9}$ : the more common variant is a granulomatous inflammation of the inner half of the media centred on the internal elastic membrane with fragmentation of this internal elastic membrane together with the specific giant cells (Fig 2B).

The less common pattern is non-specific panarteritis with a mixed inflammatory infiltrate without giant cells. Naumann et $a l^{10}$ describe the inflammatory infiltration of the adventitia expanding to the outer media as an early sign of arteritis temporalis consistent with Jennings's observations. ${ }^{11}$ 
We observed the hyporeflexive halo around the artery in three patients. Two have already had a decline of vision. Therefore, the ocular arteries can no longer provide the sole early sign.

Another method presented by Schmidt et $a l^{12}$ and by Kraft $e t a l^{13}$ is colour duplex sonography (5-10 MHz). They also revealed the characteristic halo in 22 of 30 patients (Kraft et al: 10 patients) indicating the diagnosis of giant cell arteritis (verified by histology in 16 of 21 patients (Kraft et al: five verified)). In the healed phase together with steroid treatment, the histology shows a considerable scarring. ${ }^{9}$ This halo may be due to an oedema of the artery wall and it disappears 10-14 days after the commencement of corticosteroid therapy. ${ }^{12} 13$

In 1997, Wenkel and Michelson ${ }^{14}$ reported on the use of the ultrasound biomicroscope in the diagnosis of giant cell arteritis and found the dark halo in all four patients with the histological proof (total number 16). They also found the intra-arterial "filling" and a condensation and enlargement of the muscularis media. We described the "condensation" as an increase in reflexivity of the wall, but it was observed not only in the arteritic group, but also in eight of 14 patients of the non-arteritic group. The conditions would have been different, since Wenkel and Michelson carried out the examination with an eye cup using the immersion technique - a compression of the cup cannot be ruled out. In our study, we used a special sonographic gel of low viscosity, which permits an immersion technique without real contact of the transducer with skin and a pressure-free examination.

A segmental change which was not observed in our patients could be imaged. ${ }^{13}$ Perhaps the side difference points in this direction.

Concurring with Myers and Farquhar, ${ }^{15}$ the ultrasound findings should not lead to an overestimation of the new diagnostic test. It is important to compare the results with the current diagnostic criteria (use of American College of Rheumatology criteria, performance of temporal artery biopsy). Detailed imaging can sometimes be complicated by arteriosclerotic changes. The highly reflexive arterioscle- rotic plaques extinguished the ultrasound waves, preventing the imaging of deeper areas.

We can therefore safely assume that wall reflexivity as well as the lumen and wall dimensions provide no indication of possible arteritis. Arteritic changes coincide with a side difference, a dark halo, or an intra-arterial filling. UBM imaging allows only a magnification of about eight times - that corresponds with a low magnification in light microscopy. A cellular diagnosis - for example, of the pathognomonic giant cells, is not possible.

For the moment, we need to clarify the specific, but varying, pathological changes in patients with giant cell arteritis. This variation of inflammation signs makes the non-invasive biomicroscopic diagnosis extremely difficult. Further observations in a larger number of patients are needed.

1 Schmidt D. Arteriitis temporalis Horton; Diagnose, Differentialdiagnose, Therapie. St Gallen: Elphas Buchverlag, 1995.

2 Hunder GG, Bloch DA, Michel BA, et al. The American College of Rheumatology 1990 criteria classification of the giant-cell arteritis. Arthritis Rheum 1990;33:1122-8.

3 Siemssen SJ. On the occurence of necrotising lesions in temporal arteritis: review of the literature with a note on the potential risk of a biopsy. Br f Plast Surg 1987;40:73-82.

4 Slavin ML. Brow droop after superficial temporal artery biopsy. Arch Ophthalmol 1986;104:1127.

5 Vollrath-Junger C, Gloor B. Warum eine Dopplersonographie vor jeder Biopsie der A. temporalis? Klin Monatsbl Augenheilkd 1989;195:169-71.

6 Horwitz HM, Pepe PF, Johnsrude IS. Temporal angiography and immunofluorescence as diagnostic tools in graphy and immunofluorescence as diagnos

7 Brosig J, Holtkamp A, Clemens S. Possibilities and limits in Brosig J, Holtkamp A, Clemens S. Possibilities and limits in
the imaging of extracranial vessels with conventional ultrasonography. Klin Monatbl Augenheilkd 1997;211:301-5.

sonography. Klin Monatbl Augenheilkd 1997;211:301-5.
8 Dörnberger V, Dörnberger G, Rössler R, et al. Dopplersonographie in der Diagnostik und Therapie der Arteriitis temporalis. Med Welt 1987;38:1302-8.

9 Cotran RS. Giant-cell (temporal) arteritis. In: Robbins pathologic basis of disease. 6th ed. Philadelphia: WB Saunders 1999;12:516-18.

10 Naumann GOH, Apple DJ, Wenkel H. Nervus opticus: Riesenzellarteriitis (Arteriitis temporalis). In: $\mathrm{GOH}$ Naumann, ed. Pathologie des auges II. 2nd ed. Berlin: Springer Verlag, 1997:1207-13.

11 Jennings GH. Symptoms of temporal arteritis. BMf 1953;2: 1217.

12 Schmidt WA, Kraft HE, Vorpahl K, et al. Color Duplex ultrasonography in the diagnosis of the temporal arteritis. ultrasonography in the diagnosis

13 Kraft HE, Moller DE, Volker L, et al. Color Doppler ultrasound of the temporal arteries-a new method for diagnosing temporal arteritis. Klin Monatsbl Augenheilk 1996;208: 93-5

14 Wenkel H, Michelson G. The use of ultrasound biomicroscopy in the diagnosis of giant-cell arteritis. Klin Monatsbl Augenheilkd 1997;221:48-52.

15 Myers KA, Farquar DR. Ultrasonography in temporal arteritis (letter). N Engl $\mathcal{F}$ Med 1998;338:760; discussion 761. 